\title{
Dificuldades e prazeres de uma publicação
}

\author{
Maria Cristina Castilho Costa \\ Doutora em Ciências Sociais pela FFLCH-USP, livre-docente em Ciências da Comunicação \\ pela ECA-USP, é bolsista de produtividade pelo CNPq e autora do livro Educação, \\ imagem e mídias, da Editora Cortez. \\ E-mail: criscast@usp.br
}

Resumo: Nesta apresentação, a autora comenta a produção editorial da revista Comunicação \& Educação e seu perfil editorial, que tem uma estrutura complexa, com diversas seções, cada uma com uma finalidade, um trabalho de pesquisa, uma forma de diálogo com o leitor. Cada seção tem sua especificidade nessa área de inter-relação entre comunicação e educação, de maneira a aprimorar o uso das mídias e, consequentemente, as práticas educativas do país. A intenção é sempre chamar a atenção do leitor para esse esforço de discussão e diálogo sobre mídia, cultura, educação, política e ação social. Anuncia algumas conquistas recentes, como a notícia divulgada pelo Portal de Revistas Univerciencia.org de que este periódico é o mais acessado em um portal que abriga e indexa 21 revistas brasileiras de comunicação, numa expressiva liderança em visitas, acessos e downloads.

Palavras-chave: comunicação, educação, cultura, mídia, política.
Abstract: In this presentation, the author comments on the editorial production of Comunicação \& Educação scientific journal and its editorial profile, which has a complex structure with several sections, each with a particular purpose, a research work, a form of dialogue with the reader. Each section has its specificity in the interrelation between education and communication, in order to improve the use of media and, consequently, the educational practices in the country. The purpose is always to call the reader's attention to this effort in promoting discussion and dialogue on media, culture, education, politics and social action. The paper announces some recent gains, as the report published by the portal of journals Univerciencia.org that Communicação \& Educação is the most accessed journal in the portal that collects 21 Brazilian communication journals, in a significant lead in visits, accesses and downloads.

Keywords: communication, education, culture, media, politics.

Sempre que terminamos a edição de um novo número da revista Сomunicação $\mathcal{E}$ Educação sentimos a grande satisfação do dever cumprido, pois sabemos quantos obstáculos foram superados para que ele chegasse até ali para ser encaminhado à Editora Paulinas e, finalmente, às mãos de nossos leitores. Ao contrário de alguns dos outros periódicos científicos, Comunicação $\mathcal{E}$ E Educação não é uma simples reunião de ensaios; tem uma estrutura complexa, com diversas seções, cada uma com um perfil editorial, uma finalidade, um trabalho de pesquisa, uma forma de diálogo com o leitor. Cada seção tem sua especificidade - para Artigos Nacionais, muitos originais são recebidos, lidos, 
comentados pelos pareceristas, retornando, por vezes, ao autor para necessários ajustes. Essa triagem faz com que possamos divulgar sempre temas novos, atualizados, pertinentes e sérios. Artigo Internacional passa pelo mesmo trabalho de edição, aliado às dificuldades de contato com autores estrangeiros com os quais, muitas vezes, só mantemos relações on-line. A seção de Gestão da Comunicação é elaborada juntamente com os alunos do Curso de Especialização Lato Sensu Gestão da Comunicação, no intuito de divulgar os projetos mais interessantes apresentados em cada turma. Essa seção exige que conheçamos os trabalhos apresentados, selecionemos os melhores e orientemos sua transformação em artigo. A Entrevista é uma seção que exige trabalho - a escolha do nome a ser entrevistado, o contato com a pessoa para avaliar sua disponibilidade, criação da pauta, entrevista e edição. Depoimento também requer esse trabalho prévio de escolha do depoente, do tema a ser tratado, o contato pessoal e edição do depoimento. A seção Experiência é elaborada a partir de textos que nos são enviados por professores que desenvolveram projetos pedagógicos em sala de aula - esse texto é também editado e para isso estabelecemos contato direto com o autor ou autora. Poesia e Crítica são seções muito peculiares que exigem a escolha de um nome, pesquisa, acompanhamento do texto e edição final das matérias. Tudo isso com a preocupação de não nos repetirmos, sermos atuais e satisfazermos o leitor, sem cansá-lo, dando-lhe a sensação sempre de muita novidade. As seções finais de indicações bibliográficas, videográficas e de serviços exigem que estejamos sempre em dia com o que está sendo publicado e apresentado no país e no mundo. Finalmente, quando tudo está editado, vem o trabalho pedagógico da Professora Ruth Itacarambi, que analisa esse material, procurando colocá-lo à disposição da prática do professor.

Como a revista Comunicação Ė Educação é quadrimestral, temos três meses para preparar todas as seções e enviá-las à Editora. Os entraves são muitos - as férias escolares, por exemplo, provocam um retardo no recebimento de artigos e pareceres; as dificuldades em reunir a Comissão de Publicação para tomada de decisões também prejudica a dinâmica editorial da revista; nem sempre a agenda dos entrevistados e depoentes é compatível com nosso trabalho; sem contar pequenos imprevistos como viagens de trabalho da equipe responsável pela revista. Quero lembrar ainda que uma revista com dezesseis anos como a nossa precisa de um esforço sobressalente para manter a qualidade dos textos e temas, sem nos repetirmos e, sempre, e cada vez mais, respeitando nosso leitor. Por tudo isso, o fechamento de um número é para nós sempre cercado de satisfação.

Ver o trabalho bem realizado faz com que sintamos novo ânimo a cada número que se encerra e que faz recomeçar nossa labuta. Mas, muitas vezes, mesmo fazendo esse trabalho com a seriedade e o empenho necessários, não temos certeza de estarmos acertando. O que pensa nosso leitor quando o número lhe chega às mãos, como repercute nele nossa publicação? É por isso que, quando tomamos conhecimento de um processo avaliativo da revista, temos o maior cuidado em perceber se estamos alcançando nossos objetivos. Recentemente, recebemos do Portal de Revistas Univerciencia.org ${ }^{1}$, em que os 
Dificuldades e prazeres de uma publicação • Maria Cristina Castilho Costa

nossos números já distribuídos e esgotados são disponibilizados para consulta on-line, uma gratificante análise de nosso desempenho².

Esse portal, lançado em outubro de 2008, é responsável pela indexação de revistas da área da comunicação e conta hoje com 21 títulos editados no Brasil. Nossa revista já possui 30 edições disponíveis por acesso eletrônico ${ }^{3}$, sendo o periódico com maior quantidade de documentos e informações.

\begin{tabular}{|c|c|c|c|c|c|c|c|c|c|}
\hline \multirow[t]{2}{*}{ Revistas } & \multirow{2}{*}{2008} & \multicolumn{7}{|c|}{2009} & \multirow[t]{2}{*}{ Total } \\
\hline & & Jan. & Fev. & Mar. & Abr. & Maio & Jun. & Jul. & \\
\hline Comunicação \& Educação & 1.161 & 829 & 1.112 & 875 & 760 & 1.556 & 1.475 & 2.622 & 10.390 \\
\hline Galáxia & 1.096 & 560 & 923 & 1.880 & 1.057 & 1.001 & 687 & 726 & 7.930 \\
\hline Libero & 1.001 & 235 & 266 & 534 & 688 & 1.584 & 1.331 & 798 & 6.437 \\
\hline Revista FAMECOS & 996 & 180 & 218 & 516 & 577 & 1.202 & 1.234 & 1.085 & 6.008 \\
\hline Anagrama & --- & --- & -- & -- & --- & 46 & 530 & 1.446 & 1.794 \\
\hline Comunicação \& Sociedade & 991 & 146 & 195 & 496 & 414 & 1.146 & 1.033 & 865 & 5.286 \\
\hline Comunicação, Mídia e Consumo & 988 & 325 & 368 & 459 & 451 & 739 & 668 & 785 & 4.783 \\
\hline Rastros & 979 & 98 & 281 & 704 & 390 & 282 & 348 & 529 & 3.611 \\
\hline Media e Jornalismo & 945 & 16 & 90 & 601 & 416 & 591 & 441 & 443 & 3.543 \\
\hline Em Questão & 1.025 & 131 & 163 & 401 & 278 & 463 & 340 & 454 & 3.255 \\
\hline Organicom & 963 & 105 & 210 & 409 & 195 & 291 & 342 & 262 & 2.777 \\
\hline Fronteiras & 966 & 102 & 138 & 273 & 235 & 216 & 273 & 485 & 2.688 \\
\hline Estudos em Jornalismo e Mídia & 963 & 64 & 114 & 263 & 205 & 313 & 302 & 357 & 2.581 \\
\hline Verso e Reverso & -- & 203 & 254 & 410 & 344 & 380 & 424 & 494 & 2.509 \\
\hline $\begin{array}{l}\text { Acervo On-Line de Mídia } \\
\text { Regional }\end{array}$ & 985 & 85 & 115 & 290 & 187 & 224 & 170 & 277 & 2.333 \\
\hline Contracampo & 950 & 39 & 30 & 229 & 210 & 162 & 238 & 303 & 2.161 \\
\hline E-Com & 996 & 135 & 131 & 171 & 152 & 179 & 162 & 199 & 2.125 \\
\hline MATRIZes & 950 & 41 & 79 & 163 & 147 & 226 & 189 & 169 & 1.964 \\
\hline OBServatorio & 949 & 24 & 29 & 66 & 37 & 59 & 342 & 97 & 1.603 \\
\hline REBEJ & 923 & 12 & 52 & 64 & 101 & 96 & 47 & 72 & 1367 \\
\hline Rumores & - & --- & $-\ldots$ & - & - & - & - & 229 & 229 \\
\hline TOTAL & 17.827 & 3.330 & 4.768 & 8.850 & 7.374 & 12.156 & 11.840 & 12.792 & 78.937 \\
\hline
\end{tabular}

Quadro 1: Distribui o mensal das visitas ao Portal Univerciencia.org dez. 2008/jul. 2009.

Fonte: FERREIRA, S. M. S. P.; TARGINO, M. G. M tricas alternativas de avalia o do impacto e do uso de revistas eletr nicas: estudo em ciĺ ncias da comunica o. In: FERREIRA, S. M. S. P.; TARGINO, M. G. (Org.). Acessibilidade e visibilidade de revistas científicas eletrônicas. S o Paulo: Senac/CENGAGE, 2010. No prelo.

Segundo Relatório Estatístico realizado pelos mantenedores do Portal, os visitantes perfazem uma média de 267 visitas/dia, sendo a revista Comunicação E̊ Educação a campeã de acessos - de dezembro de 2008 a julho de 2009, recebeu 10.390 pageviews e 32.805 downloads de artigos. Informação importante desse levantamento estatístico mostra que os textos mais antigos são ainda os mais

2. FERREIRA, S. M. S. P. TARGINO, M. G. Métricas alternativas de avaliação do impacto e do uso de revistas eletrônicas: estudo em ciências da comunicação. In: FERREIRA S. M. S. P.; TARGINO, M. G. (Org.). Acessibilidade e visibilidade de revistas científicas eletrônicas. São Paulo: Senac/CENGAGE, 2010. No prelo.

3. Disponível em: <http:// www.revistas.univerciencia.org/index.php/comeduc/index $>$. 
consultados pelos visitantes. Isso significa que a revista Comunicação $\mathcal{E}$ Educação, em importante portal de periódicos de comunicação, mantém expressiva liderança em visitas, acessos e downloads.

\begin{tabular}{|c|c|c|c|c|c|c|c|c|c|}
\hline \multirow{2}{*}{ Revistas } & \multicolumn{4}{|c|}{2008} & \multicolumn{4}{|c|}{2009} & \multirow{2}{*}{ Total } \\
\hline & Dez. & Jan. & Fev. & Mar. & Abr. & Maio & Jun. & Jul. & \\
\hline $\begin{array}{l}\text { Comunicação \& } \\
\text { Educação }\end{array}$ & 3.782 & 4.117 & 2.663 & 4.337 & 3.084 & 1.923 & 4.661 & 8.238 & 32.805 \\
\hline Revista FAMECOS & 1.923 & 2.296 & 1.186 & 2.973 & 2.426 & 1.893 & 3.381 & 6.428 & 22.506 \\
\hline Galáxia & 1.500 & 2.971 & 2.375 & 4.156 & 2.759 & 2.200 & 2.505 & 3.544 & 22.010 \\
\hline $\begin{array}{l}\text { Comunicação, Mídia e } \\
\text { Consumo }\end{array}$ & 894 & 1.696 & 855 & 1.409 & 1.382 & 1.783 & 2.215 & 3.092 & 13.326 \\
\hline Libero & 787 & 976 & 891 & 1.319 & 1.300 & 1.843 & 2.084 & 2.620 & 11.820 \\
\hline Em Questão & 1.285 & 1.028 & 670 & 1.591 & 1.465 & 1.224 & 1.397 & 2.434 & 11.094 \\
\hline $\begin{array}{l}\text { Comunicação \& } \\
\text { Sociedade }\end{array}$ & 717 & 668 & 638 & 1.271 & 1.139 & 1.483 & 1.771 & 2.127 & 9.814 \\
\hline Anagrama & -- & -- & -- & 125 & 966 & 1.559 & 2.508 & 3.436 & 8.594 \\
\hline $\begin{array}{l}\text { Estudos em Jornalismo } \\
\text { e Mídia }\end{array}$ & 207 & 997 & 463 & 1.309 & 821 & 897 & 1.258 & 1.882 & 7.834 \\
\hline Fronteiras & 655 & 715 & 545 & 1.026 & 967 & 670 & 1.155 & 2.016 & 7.749 \\
\hline Rastros & 494 & 512 & 580 & 1.291 & 762 & 473 & 819 & 1.218 & 6.149 \\
\hline Media e Jornalismo & 115 & 182 & 339 & 865 & 864 & 1.055 & 1.158 & 1.436 & 6.014 \\
\hline Organicom & 349 & 301 & 340 & 624 & 325 & 427 & 623 & 505 & 3.494 \\
\hline Contracampo & 226 & 274 & 121 & 523 & 423 & 335 & 611 & 788 & 3.301 \\
\hline Verso e Reverso & 175 & 287 & 208 & 458 & 380 & 418 & 514 & 611 & 3.051 \\
\hline MATRIZes & 121 & 270 & 194 & 456 & 376 & 433 & 468 & 670 & 2.988 \\
\hline $\begin{array}{l}\text { Acervo On-Line de } \\
\text { Mídia Regional }\end{array}$ & 273 & 281 & 186 & 407 & 337 & 303 & 359 & 738 & 2.884 \\
\hline OBServatorio & 307 & 359 & 164 & 380 & 274 & 278 & 394 & 715 & 2.871 \\
\hline E-Com & 383 & 360 & 221 & 379 & 336 & 277 & 338 & 526 & 2.820 \\
\hline REBEJ & 117 & 191 & 152 & 284 & 319 & 320 & 214 & 321 & 1.918 \\
\hline Rumores & - & -- & -- & - & - & 2 & 16 & 793 & 811 \\
\hline TOTAL & 14.310 & 18.481 & 12.791 & 25.183 & 20.705 & 19.796 & 28.449 & 44.138 & 183.853 \\
\hline
\end{tabular}

Quadro 2: N mero de downloads do Portal Univerciencia.org por revista dez. 2008/jul. 2009.

Fonte: FERREIRA, S. M. S. P.; TARGINO, M. G. M tricas alternativas de avalia o do impacto e do uso de revistas eletr nicas: estudo em ciĺ ncias da comunica o. In: FERREIRA, S. M. S. P.; TARGINO, M. G. (Org.). Acessibilidade e visibilidade de revistas científicas eletrônicas. S o Paulo: Senac/CENGAGE, 2010. No prelo.

Essa posição é tão mais importante quando levamos em consideração a dificuldade da divulgação científica no país, assim como a sobrevida de uma revista científica por mais de dez anos.

Assim, diante desses resultados nos sentimos honrados com o trabalho realizado e temos a satisfação de, a cada quatro meses, preparar nova edição para nossos leitores. Vamos, então, ao número que ora apresento. 
Dificuldades e prazeres de uma publicação - Maria Cristina Castilho Costa

\section{PESQUISA EM ANDAMENTO: PROFESSORES E CULTURA DIGITAL}

Adilson Odair Citelli é o autor de um dos ensaios deste número - trata-se de apresentação comentada dos resultados de sua pesquisa a respeito de como os jovens professores de até 30 anos, trabalhando no Ensino Fundamental e Médio, incorporam e reagem ao surgimento das mídias digitais e as introduzem em suas práticas pedagógicas. O autor, professor e pesquisador, desenvolve essa investigação há longos anos. Os resultados que traz mostra o profícuo trabalho que vem realizando, e, a despeito de a cultura digital ter presença frequente nas páginas de Comunicação Ė Educação, é sempre muito bom ver o assunto tratado à luz de dados científicos.

\section{IMAGEM E CIÊNCIA}

Ligadas à expansão do entretenimento, à vida cotidiana e à cultura de massa, as imagens sempre tiveram uma relação ambígua de aproximação e distanciamento em relação ao desenvolvimento da ciência. Fotografia e cinema foram apropriados pela sociedade e pelo público em geral de forma muito mais rápida do que pelos intelectuais e cientistas. O texto de Maria Cristina Castilho Costa procura debater essa relação mostrando como a imagem foi sendo adotada pelos cientistas sociais, especialmente os etnógrafos, interessados em conhecer e descrever povos não europeus. A transformação da fotografia em objeto da ciência é tema deste ensaio.

\section{EM BUSCA DO PÚBLICO}

A expansão do socialismo e, em especial, a Revolução Russa foram fatores essenciais para um fenômeno que dominou a produção artística do século XX - a politização da arte. Encarar a produção artística não como entretenimento ou fuga, mas como meio de conscientização do público foi preocupação de grande parte dos artistas, entre os quais Brecht, que propõe um teatro engajado e revolucionário. Como afirma o autor Celso Frederico, essa postura se desenvolve concomitantemente à implantação dos meios de comunicação de massa e, também, ao seu uso político e revolucionário.

\section{LEITURAS E LEITORES}

A relação dos autores com o público é tema recorrente entre estudiosos das ciências da comunicação. Eneus Trindade e Sérgio Annibal, nessa perspectiva, apresentam um ensaio que disserta a respeito da leitura e da produção de sentido. Abordando de forma histórica e epistemológica o tema, os autores discorrem sobre recepção midiática e processos de leitura em diferentes mídias. 
comunicação \& educação • Ano XV • Número 1 • jan/abr 2010

\section{BRINQUEDOS E IDENTIDADE INFANTIL}

O ensaio de Juliana Pereira de Sousa trabalha o brinquedo infantil e sua importância na sociedade contemporânea marcada por sua cultura midiática e de consumo, mas procura também analisá-lo como fonte de identidade da criança nesse mundo de comunicação e mídias.

\section{ARTIGO INTERNACIONAL}

Fernando Barone, professor e pesquisador atuante em Portugal, disserta a respeito da sociedade contemporânea em que a identidade infantil se vê produzida através de instituições tradicionais como a família e a escola, mas também por meio das mensagens midiáticas que constroem, a respeito da criança, uma imagem espetacularizada. Além disso, ele nos apresenta resultados de estudos a respeito de mídia e educação.

\section{O VELHO E O NOVO PORTO DE SANTOS}

Katherine Realle Nóbrega de Andrade, gestora de comunicação, trabalha em uma das empresas que administram o Porto de Santos, em São Paulo. Do trato cotidiano com os trabalhadores da empresa, ela pôde entender o impacto das transformações ocorridas nestes últimos anos de neoliberalismo e privatização, numa das mais importantes instituições de luta trabalhista. Seu artigo relata esse processo e mostra o que a comunicação pode fazer para administrar os conflitos por ele gerados.

\section{EDUCOMUNICAÇÃO NA ITÁLIA}

Já tivemos oportunidade de mostrar que a educomunicação não é um tema importante apenas no Brasil - na América Latina e na Europa, há pesquisadores interessados na inter-relação entre comunicação e educação. Na seção entrevista, Isabella Bruni, que veio ao Brasil para conhecer nossas experiências sobre o tema, fala sobre diferenças e semelhanças entre Itália e Brasil, nesse quesito.

\section{SARAU DO BINHO}

O depoente deste número da revista Comunicação $\mathfrak{E}$ Educação é Binho, que teve importante iniciativa cultural junto à população de seu bairro, Campo Limpo, periferia da Cidade de São Paulo. O Sarau do Binho reúne pessoas de diversos bairros e de cidades vizinhas interessadas em cultura - dando origem inclusive a movimentos que se espalham por outras regiões do estado. Trata-se de um espaço democrático no qual os que quiserem podem cultivar poesia e literatura. Em seu depoimento, o idealizador do Sarau explica como chegou lá. 
Dificuldades e prazeres de uma publicação - Maria Cristina Castilho Costa

\section{A DESCONSTRUÇÃO DA MITOLOGIA DO AUTOMÓVEL}

Em Mr. Hulot e a desconstrução da mitologia do automóvel: uma análise de "Trafic", de Jacques Tati, o autor Vander Casaqui dá continuidade à Crítica iniciada no número anterior de Comunicação $\mathcal{E}^{2}$ Educação, e justifica-se pelo tema que está perseguindo: as relações comunicação, educação e consumo, caminho para a formação do sujeito participante na sociedade, com consciência, com criticismo. $\mathrm{O}$ artigo desenvolve uma análise do filme Trafic, a partir do qual trata das questões do consumo, do mundo do trabalho e das intrincadas relações entre sujeitos e mercadorias no contexto contemporâneo. O quadro teórico é baseado nos estudos de Roland Barthes e Jean Baudrillard, entre outros autores, que analisam os processos simbólicos que envolvem os bens, da esfera produtiva aos cenários socioculturais que revestem seu consumo pelos sujeitos.

\section{FORMALISMO RUSSO EM SALA DE AULA}

Carolina Duarte Damasceno traz para nossos leitores experiência inovadora - introdução à linguagem poética, feita a partir da teoria de Chklovski, importante nome do formalismo russo -, em duas turmas de $8^{\underline{a}}$ série do Ensino Fundamental. A autora nos mostra como é possível trabalhar com a noção de estranhamento com os alunos, aproximando a realidade deles do mundo literário.

\section{A POESIA DE MÁRIO FAUSTINO}

Apesar de menos conhecido do que outros poetas seus contemporâneos, Mário Faustino teve em sua meteórica carreira importante influência sobre a literatura do país, sendo perceptível o traço de seus versos em outros poetas brasileiros. Em razão dessa importância e da qualidade de seus poemas, a revista Comunicação E̊ Educação dedica-lhe a seção Poesia deste número.

\section{MUSEU AFRO BRASIL}

O interesse de Emanoel Araújo pela cultura afro-brasileira não é de hoje - há muito ele coleciona obras de arte e manifestações culturais que revelam a riqueza dessa herança que é um dos pilares de nossa cultura. Sua coleção, que reúne cerca de cinco mil obras, entre pinturas, esculturas, gravuras, fotografias, livros, vídeos e documentos, de artistas e autores brasileiros e estrangeiros, relacionados com a temática do negro, foi a base do Museu Afro Brasil, que tem no artista seu diretor e curador. Esse museu é apresentado neste número na seção Serviços.

\section{CINEMA E SERTÃO}

Para gáudio dos professores de história, geografia, sociologia, entre outros, o cinema brasileiro tem dedicado muitas obras ao estudo do sertão brasileiro, 
fonte inesgotável de cenários, vivências, conflitos e brasilidade. É isso que nos mostra Maria Ignês Carlos Magno na seção Videografia.

\section{TRABALHANDO COM ESTE NÚMERO EM SALA DE AULA}

Como procurei mostrar no início desta Apresentação, cada seção tem uma finalidade, um processo editorial, um responsável, uma missão. A última delas é a que mais se aproxima de nosso leitor, pois prepara cada artigo para um trabalho educativo que pode ser realizado na sala de aula, em casa ou na empresa. Para isso, contamos com a engenhosidade de Ruth Ribas Itacarambi e a criatividade de nossos leitores.

\section{REFERÊNCIAS BIBLIOGRÁFICAS}

FERREIRA, S. M. S. P.; TARGINO, M. G. Métricas alternativas de avaliação do impacto e do uso de revistas eletrônicas: estudo em ciências da comunicação. In: FERREIRA, S. M. S. P.; TARGINO, M. G. (Org.). Acessibilidade e visibilidade de revistas científicas eletrônicas. São Paulo: Senac/CENGAGE, 2010. No prelo.

\section{Endereços eletrônicos}

UNIVERCIENCIA.ORG. Disponível em: <http://www.univerciencia.org/> .

PORTAL DE REVISTAS. Revistas de acesso aberto em Ciências da Comunicação. Revista Comunicação Ė Educação. Disponível em:<http:/ / www.revistas.univerciencia. org/index.php/comeduc/index >. 